Kevin Gibbons, M.D., Anand Singh, M.D.,

M. Abraham Kuriakose, M.D., Thom R. Loree, M.D.,

Kenneth Harris, B.S., Ari Rubenfeld, B.S.,

Samuel Goodloe, Jr., M.D., and

Wesley L. Hicks, Jr., D.D.S., M.D., F.A.C.S.

\title{
Giant Cell Tumor of the Infratemporal Fossa
}

\begin{abstract}
Giant cell tumors are an uncommon neoplasm; most are found in the long bones, formed by endochondral ossification. This article presents a case of giant cell tumor of the infratemporal fossa, which by radiographic and clinical examination appears to have originated in the squamous portion of the temporal bone.
\end{abstract}

Giant cell tumors are uncommon neoplasms. Their usual clinical presentation is in the long bones formed by endochondral ossification (90\%). ${ }^{1}$ The incidence of giant cell tumors within the facial skeleton is low $(2 \%){ }^{2}$ Reported cases of giant cell tumors of the facial skeleton typically involve the maxilla, mandible, or sphenoid portion of the temporal bone. ${ }^{3,4}$ Giant cell tumors of the calvarium (formed by membranous ossification) or infratemporal fossa are exceedingly rare clinical entities. ${ }^{5,6,12}$ This article presents a case of giant cell tumor of the infratemporal fossa, which by radiographic and clinical examination appears to have originated in the squamous portion of the temporal bone.

\section{CASE REPORT}

A 44-year-old African-American male presented in May 1994 with a 2-week history of progressively wors- ening unilateral hearing loss, vertigo, and tinnitus, as well as intermittent clear otorrhea and an associated otalgia of his right side.

His general physical examination was that of a healthy male in no acute distress. The head and neck examination was remarkable for the following findings. His right ear had a violaceous friable lesion of the cartilagenous external auditory canal that obscured the view of the tympanic membrane. His audiogram demonstrated a moderate to severe sensorineural hearing loss with a left lateralizing Weber examination. There was also decreased sensation to pinprick and light touch on the right side of the patient's face in the distribution of the mandibular branch of the trigeminal nerve. His masseteric tone on the right was diminished, and he was unable to maintain a constant biting force. There was evidence of slight weakness of the lower division of the facial nerve on the right side. The remainder of his head and neck examination was unremarkable.

Skull Base Surgery, Volume 10, Number 3, 2000 Department of Head and Neck Surgery, Roswell Park Cancer Institute, Buffalo, New York, NY (AS, MAK, TRL, KH, AR, WLH); Departments of Neurosurgery (KG) and Pathology (SG), Millard Filmore Hospital, Buffalo, NY. Reprint requests: Dr. Hicks, Jr., Department of Head and Neck, Roswell Park Cancer Institute, Elm and Carlton Streets, Buffalo, New York, NY 14263. Copyright (c) 2000 by Thieme Medical Publishers, Inc., 333 Seventh Avenue, New York, NY 10001, USA. Tel.: +1(212) 584-4662. 1052-1453,p;2000,10,03,155,158,ftx,en;sbs00181x 
CT demonstrated a large destructive radiolucent lesion of the right infratemporal region, with medial extension to the middle cranial fossa, the right cochlea, and semicircular canals (Figs. 1 and 2). The temporal lobe was pushed medially by the tumor with no radiographic evidence of parenchymal invasion. CT-guided fine-needle aspiration cytology was consistent with giant cell tumor.

\section{Surgical Management}

The preoperative radiologic and clinical assessment led us to believe that this tumor was resectable with negative margins. The tumor was excised using a Fish-type II approach. Intraoperative assessment demonstrated involvement of the petrous portion of the temporal bone, dura over the temporal lobe the glenoid fossa, parotid gland, and the temporalis muscle. The patient underwent isolation of the internal carotid artery; total parotidectomy with preservation of facial nerve and resection of the glenoid fossa and the mandibular condyle, cortical mastoidectomy with amputation of the bony and cartilaginous external auditory canal, and petrosectomy. The surgical defect was repaired by fascia lata grafting for repair of the dural defect and acrylic cranioplasty. The surgical margins of resection were free of tumor.

\section{Pathology}

Gross examination of the specimen showed dark gray tissue with areas of hemorrhage and calcification. Microscopic examination showed a heterogeneous cell population of multinucleated giant cells surrounded by scant hemosiderin-laden stroma consisting of fusiform fibroblasts. The giant cells were evenly distributed in clusters with eosinophilic cytoplasm (Fig. 3). Only occasional mitotic activity was noted. On permanent section, the final diagnosis of giant cell tumor was made, based on the microscopic findings of generally benign cellular cytology, the appearance of large multinucleated giant cells, and lack of sarcomatous alterations within the stromal or osteoid component of the tumor. The surgical margins were free of tumor.

\section{Postoperative Course}

On postoperative day 7 , the patient showed the development of a seroma, which resolved without sequelae. The remainder of the patient's immediate postoperative course was uneventful. Four months after surgery, he had a seizure that was witnessed. The patient is on a maintenance dose of carbamazepine and has had no further seizures. He has remained disease free for 4 years.

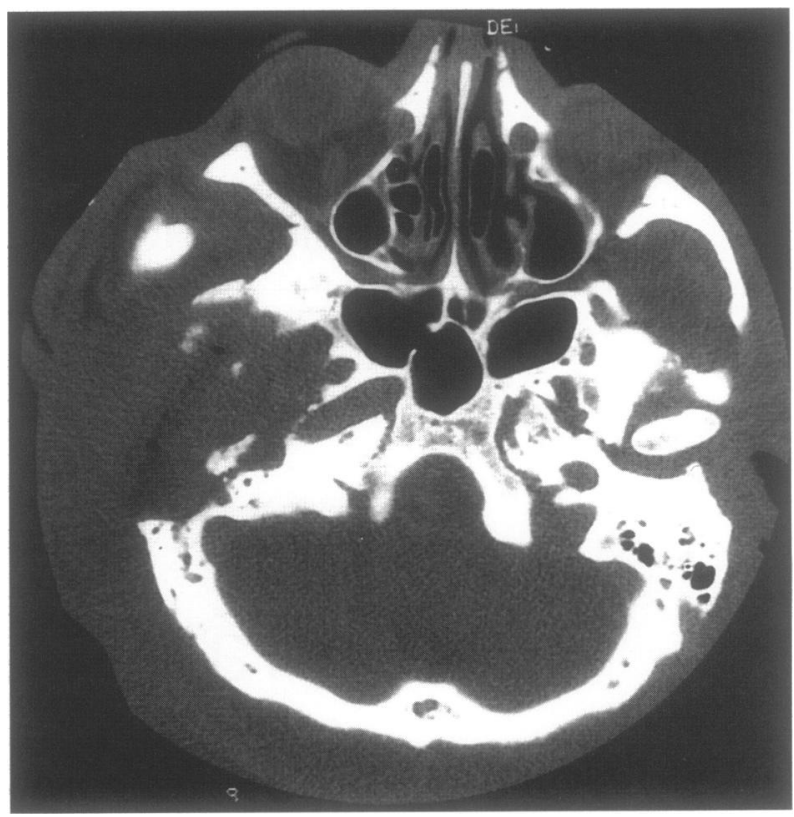

Figure 1. CT demonstrated a large destructive radiolucent lesion of the right infratemporal region, with medial extension to the middle cranial fossa, the right cochlea, and semicircular canals.

\section{DISCUSSION}

Giant cell tumors generally affect patients between the ages of 25 and 40 and occur slightly more frequently in females. ${ }^{1}$ Giant cell tumors of the facial skeleton are often clinically occult and, although considered benign, can cause extensive local destruction.

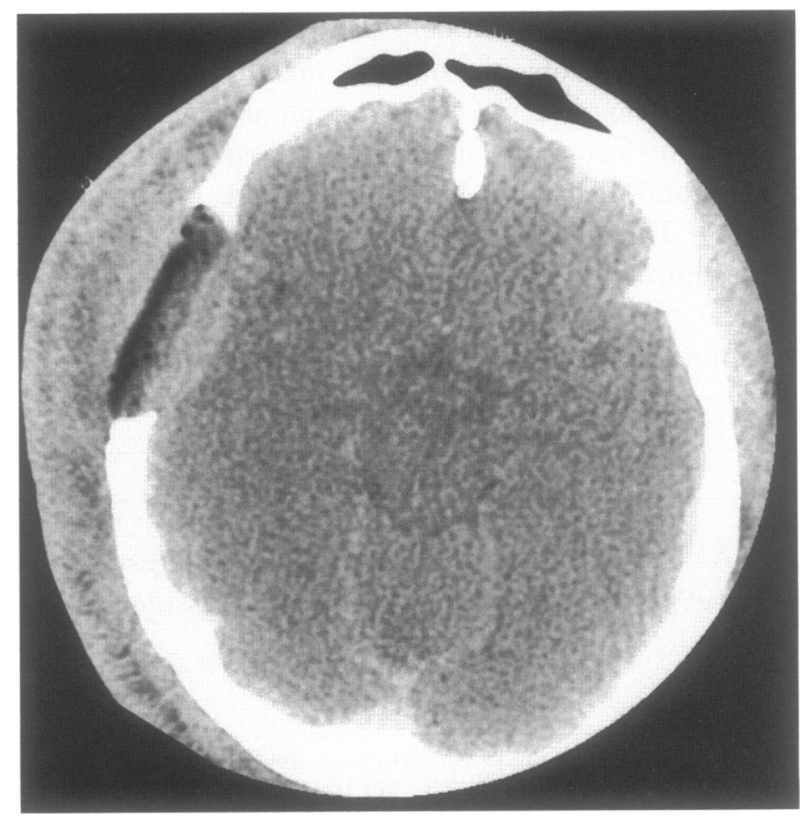

Figure 2. CT showing full-thickness destruction of temporal bone with intracranial extension of the lesion. 


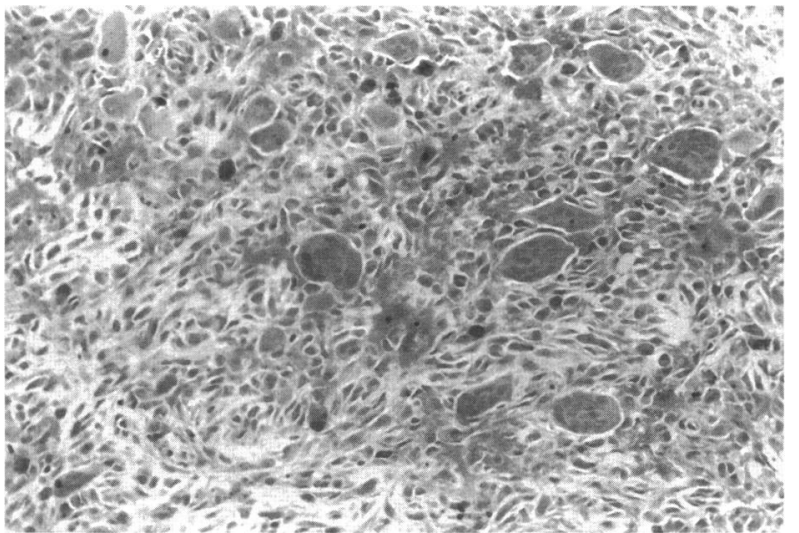

Figure 3. Photomicrograph showing clusters of multinucleated giant cells and mononuclear cells in a background containing hemosiderin-laden macrophages and loose stromal connective tissue (hematoxylin \& eosin, $\times 200$ ).

Numerous theories have been proposed as to the origin of giant cell tumors. Coley and Bradley ${ }^{7}$ proposed that these tumors fit into one of three categories: neoplastic, inflammatory, or traumatic. $\mathrm{Jaffe}^{8}$ in 1940 classified giant cell tumors into two categories: those that constitute the true neoplastic process and those that are the result of an inflammatory/reparative process or "epulis." Under this classification, giant cell tumors originate in the connective tissue of the bone marrow, whereas the reparative lesion arises from the periosteum. Although an appealing hypothesis as to the pathophysiology of these lesions, because of their often occult nature and extensive destruction within the facial skeleton by the time of diagnosis and treatment, periosteal lesions cannot be differentiated either clinically or radiologically from marrow lesions.

Histopathologically, giant cell tumors must be differentiated from osteogenic sarcomas, malignant fibrous histiocytomas, chondromyxoid fibromas, aneurysmal bone cysts, and the brown tumor associated with hyperparathyroidism. Giant cell reparative granuloma is a self-limiting lesion that undergoes spontaneous remission. The age of disease presentation in these patients is younger (10 to 25 years) than the age typically associated with giant cell tumor. Histologically, giant cell reparative granuloma is characterized by giant cells with fewer and smaller nuclei with abundant surrounding hemorrhagic foci, as com- pared with giant cell tumor, which consists of more prominent giant cells with few hemorrhagic foci.

Surgical excision with negative margins remains the treatment of choice for cranial giant cell tumors. Radiation therapy should be considered as adjunctive treatment in lesions that are incompletely resected or in those that are deemed inoperable. ${ }^{9}$

Curettage of these lesions is associated with an increased local recurrence rate and should be avoided as a surgical technique in this disease. McGrath ${ }^{1}$ reported that curettage alone resulted in a recurrence rate of $23 \%$, whereas those lesions resected with negative margins had only a $7 \%$ local failure rate. Malignant transformation has been reported to be as high as $29 \%$ in patients treated with radiation therapy and has not proved more efficacious in obtaining local control than surgery alone with negative margins. ${ }^{1,10,11}$

Based on the review of the literature and our own experience, it would appear that adequately resected giant cell tumor (i.e., with negative margins) without adjunctive therapy promotes satisfactory local control of disease.

\section{REFERENCES}

1. McGrath PJ. Giant cell tumors of bone: An analysis of 52 cases. J Bone Joint Surg [Br] 1972;54:216

2. Cook HF, Miller R, Yamada R. Giant cell tumor of the infratemporal fossa: Report of case. J Oral Maxillofac Surg 1986;44: 651-656

3. Pitkethly DT, Kempe LG. Giant cell tumors of the sphenoid: Report of two cases. J Neurosurg 1969;30:201-204

4. Geissinger JD, Siueira EB, Ross E. Giant cell tumors of the sphenoid bone. J Neurosurg 1970;32:665-670

5. Jelsma FR. Primary tumors of the calvaria with special consideration of the clinical problems. Springfield, IL: Charles C Thomas, 1959

5. Wilkins RH, Rengachary SS, eds. Neurosurgery. 2nd ed. New York: McGraw-Hill, 1994

7. Coley B, Bradley L. Neoplasms of Bone. 2nd ed. New York: Paul Hoeber, 1949

8. Jaffe HL. Tumors and tumorous conditions of the bones and joints. Philadelphia: Lea \& Febiger, 1958

8. Arseni C, Horvath L, Maretsis M, et al. Giant cell tumors of the calvaria. J Neurosurg 1975;42:535-540

9. Hunter RVP, Worcester JN, Francis KC, et al. Benign and malignant giant cell tumors of bone: A clinico-pathological analysis of the natural history of the disease. Cancer 1962;15:653-690

10. Mirra JM, Gold RH, Marcove RC. Primary malignant giant cell tumor of bone. Cancer 1979;44:1393-1402

11. Sanerkin NG. Malignancy, aggressiveness and recurrence in giant cell tumor of bone. Cancer 1980;46:1641-1649

12. Henderson BT, Whitwell H. Giant cell tumor of the skull: Case report. Neurosurgery 1988;23:120-122 